\title{
Thrombosis associated with internal jugular vein cannulation in diabetics and hypertensives: a prospective observational study
}

\author{
Madhava R Reddy ${ }^{1^{*}}$, Swathi Nayak ${ }^{2}$, Komala B Nethaji ${ }^{3}$ \\ Professor $^{l *}$, Resident ${ }^{2,3}$, Department of Anaesthesiology, Kempegowda Institute of Medical Sciences, \\ Bangalore, \\ Karnataka, India.
}

\begin{abstract}
Background: Thromboembolism is one of the major complications associated with central venous catheters (CVC) which is sub-clinical most of the time, hence undiagnosed leading to various life-threatening complications. Studies on catheter related thrombosis (CRT) are conducted on patients with malignant conditions and seldom been done on diabetics and hypertensives who are more commonly encountered in day to day practice. The aim of our study was to determine the rate of occurrence of CRT formation in diabetics and hypertensives.
\end{abstract}

Material and Methods: This prospective, observational, hospital-based study was conducted after obtaining clearance from institutional ethics committee. The study was carried out on 105 patients requiring CVC insertion as part of their treatment. They were divided into three groups, Group D, Group H and Group C each consisting of 35 patients with type II diabetes mellitus, hypertension and American Society of Anaesthesiologists (ASA) class 1 patients respectively. Right internal jugular vein (IJV) was cannulated and the occurrence of thrombus and its progression was noted using serial colour Doppler sonography on third, sixth and on the dayof catheter removal. Statistical analysis done using SPSS 22 version software. ANOVA and Chi-square tests were used. $\mathrm{P}<0.05$ considered statistically significant.

Results: The rate of CRT was $34.3 \%, 20 \%, 8.57 \%$ in Group D, Group H and Group C respectively. The rate of thrombus formation was statistically significant in group D compared to group $\mathrm{C}$.

Conclusions: CRT formation was observed in all the groups with statistically significant proportion in diabetics compared to ASA 1 patients.

Keywords: Catheter related thrombosis; internal jugular vein; diabetes mellitus; hypertension

\section{Introduction}

Central venous catheters (CVC) are widely used in management of patients in critical care and anaesthesia. Catheter related thrombosis (CRT) is one amongst the complications, and if undiagnosed may lead to serious sequelae.

The aetiology of CRT is multifactorial. ${ }^{1}$ Its incidence in internal jugular vein (IJV) is 40$56 \%{ }^{2}$
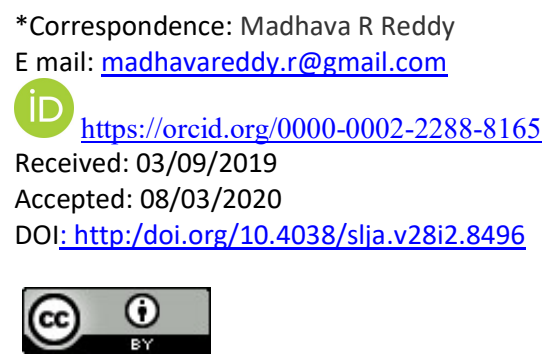

Literature reveals incidence of CRT in patients with malignancies and other prothrombotic conditions but not exclusively in diabetics and hypertensives whose prevalence is increasing among Indians and who are prone for hypercoagulable state. ${ }^{3,4,5}$ Hence, we aimed to assess the rate of catheter related thrombus formation in patients with diabetes and hypertension.

\section{Materials and methods}

After obtaining approval from institution ethics committee, 105 patients who required CVC insertion as part of their treatment in our ICU/SICU were selected for this prospective observational study and were divided into three groups of 35 each. Sample size was estimated using the incidence of CRT in previous studies and at $95 \%$ confidence level and $80 \%$ power, considering $10 \%$ non-response, a sample size of 32 patients was required in each group. 
However, we rounded up to 35 subjects in each group with Group D consisting of type II diabetics, Group H consisting of hypertensives and Group $\mathrm{C}$ the control group consisting of ASA 1 patients. Patients with pre-existing thrombus in IJV, on anticoagulant medication, known coagulation abnormalities and hypercoagulable states like malignancy, renal failure, sepsis etc, were excluded from the study. Study protocol was explained to the patients and written informed consent was taken. Patients who were incapacitated to give consent, the same was obtained from their attenders.

Colour Doppler sonography of the IJV was done using GE LogiQ E using 8-12 MHz linear probe by an experienced radiologist to rule out a preexisting thrombus. With aseptic precautions, under ultrasound guidance, right IJV was cannulated using 7F Certofix B Braun double lumen $\mathrm{CVC}$ by an experienced anaesthesiologist. Catheter tip placement was confirmed to be at the junction of SVC and right atrium. Free flow of blood was confirmed in both the lumen and the patency of the CVC was maintained as per our institutional protocol.

Serial scans were performed on third and sixth day after insertion and on the day of removal of CVC to know the formation and progression of the thrombus. Patients in whom CRT was detected were started on anticoagulant therapy as per standard protocol and were followed up for the study period and the vascular surgeon was consulted for further management. Patients in whom CVC was removed within six days of insertion for any reason were planned to be excluded from the study but catheter was not removed in any patients within six days.

Data was entered into Microsoft excel data sheet and was analysed using SPSS 22 version software. Categorical data was represented in the form of frequencies and proportions. Chi-square test for qualitative data and ANOVA test for demographic variables were used. $\mathrm{P}$ value of $<0.05$ was considered as statistically significant.

Results: Of the 105 patients screened, there were no dropouts from the study. Majority of the patients belonged to an age group of 50-70 years and there was no statistical difference in sex distribution.
Table 1: Demographic variables in three groups (ANOVA for age, chi-square test forsex)

\begin{tabular}{|c|c|c|c|c|}
\hline Variables & $\begin{array}{l}\text { Group D } \\
(\mathrm{n}=35)\end{array}$ & $\begin{array}{l}\text { Group H } \\
(\mathrm{n}=35)\end{array}$ & $\begin{array}{l}\text { Group C } \\
(\mathrm{n}=35)\end{array}$ & $\begin{array}{l}\mathrm{p} \\
\text { Value }\end{array}$ \\
\hline $\begin{array}{l}\begin{array}{l}\text { Age } \\
\text { (mean }\end{array} \\
\text { SD) }\end{array}$ & $\begin{array}{l}61.34 \quad \pm \\
12.03\end{array}$ & $\begin{array}{l}58.46 \pm \\
11.73\end{array}$ & $\begin{array}{ll}37.40 & \pm \\
10.69 & \end{array}$ & $\begin{array}{l}<0.00 \\
1\end{array}$ \\
\hline $\begin{array}{l}\text { Sex } \\
\text { Female }\end{array}$ & $19(54.3 \%)$ & $15(42.9 \%)$ & $15(42.9 \%)$ & \multirow[t]{2}{*}{0.542} \\
\hline Male & $16(45.7 \%)$ & $20(57.1 \%)$ & $20(27.1 \%)$ & \\
\hline
\end{tabular}

SD- Standard deviation $\mathrm{n}=$ number of patients Overall rate of CRT formation was $20.95 \%$ (22) of which $34.3 \%$ (12) belonged to Group D, 20\% (7) to Group H and $8.57 \%$ (3) to Group C. When compared with the control group, the rate of thrombus formation was statistically significant in group $\mathrm{D}(\mathrm{P}=0.008)$ and not statistically significant in group $\mathrm{H}$.

Table 2: Rate of CRT formation in diabetics compared to control. (chi square test.)

\begin{tabular}{|l|l|l|l|}
\hline Thrombus & Group D & Group C & $\begin{array}{l}\text { P } \\
\text { value }\end{array}$ \\
\hline Present (n-\%) & $12(34.3 \%)$ & $3(8.57 \%)$ & 0.008 \\
\hline Absent (n-\%) & $23(65.7 \%)$ & $32(91.4 \%)$ & - \\
\hline
\end{tabular}

$\mathrm{n}=$ number of patients.

Table 3: Rate of CRT formation in hypertensives compared to control (chi square test)

\begin{tabular}{|l|l|l|l|}
\hline Thrombus & Group H & Group C & P value \\
\hline Present (n-\%) & $7(20 \%)$ & $3(8.57 \%)$ & 0.172 \\
& & & \\
\hline Absent (n-\%) & $28(80 \%)$ & $32(91.4 \%)$ & - \\
\hline
\end{tabular}

$\mathrm{n}=$ number of patients

Out of 22 cases of thrombi detected, nine $(40.9 \%)$ were found on day three and three $(13.6 \%)$ on day six in group $\mathrm{D}$, four $(18 \%)$ were found on day three and three (13.6\%) on day six in group $\mathrm{H}$ and one $(4.5 \%)$ on day three and two $(9 \%)$ on day six in group C. 
Figure 1: Short axis view of right IJV shows the CVC in-situ with an echogenic thrombus seen on its anterior aspect, measuring about $3 \times 3 \mathrm{~mm}$ on day 3 after CVC insertion.

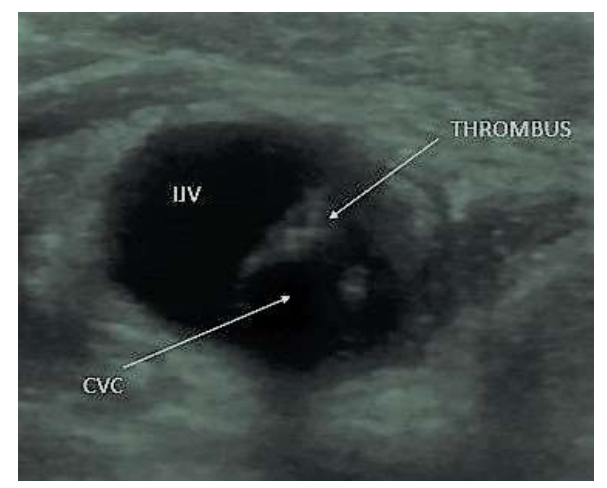

Figure 2: Long axis view of right IJV shows the CVC in-situ with an echogenic thrombus seen on its anterior aspect, measuring about $3 \times 3$ $\mathrm{mm}$ on day 3 after CVC insertion.

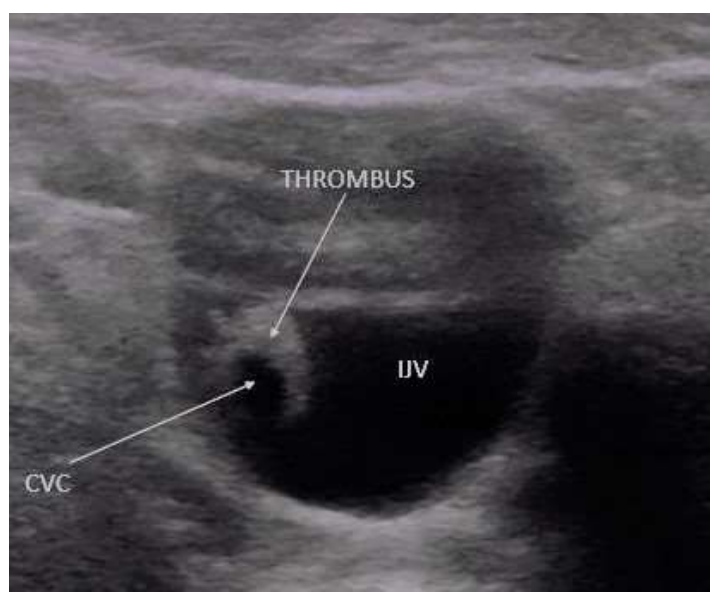

Figure 3: Short axis view of right IJV shows the CVC in-situ with a comparatively more echogenic thrombus seen on its anterior aspect, measuring about $4 \times 5 \mathrm{~mm}$ on day 6 after $\mathrm{CVC}$ insertion.

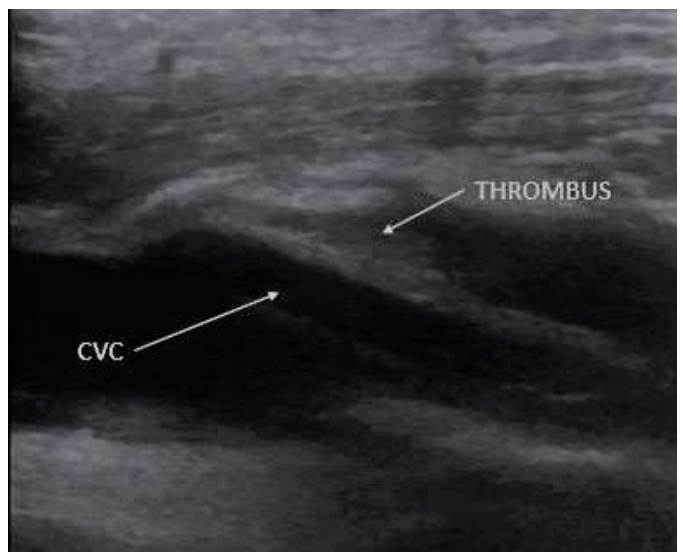

With respect to the progression of the thrombus, $58.3 \%$ in Group D, $42.8 \%$ in Group H and none in group $\mathrm{C}$ showed a progression in the size of the thrombus.

\section{Discussion}

Central venous catheters are regularly inserted in the intensive care units and during major surgeries for vascular access, haemodynamic monitoring, administration of drugs and nutritional supplementation. Though of considerable advantage the central line is also associated with life threatening complications like catheter related blood stream infections, right heart thromboembolisms, pulmonary embolisms etc. secondary to thrombus formation around the catheter. ${ }^{6}$

The pathogenesis of thrombus formation has been classically explained using Virchow's triad which consists of endothelial damage, stasis and hypercoagulability. On insertion of catheter, there is damage to the endothelium mainly at the insertion site and also along the course of the vein due to mechanical trauma to the endothelium by the catheter within the vein. Further, there is stasis of blood resulting from mechanical obstruction to laminar flow by the catheter and high viscosity of the infusate used. Along with these, the hypercoagulable state due to the patient's pre-existing condition also contributes to CRT formation. ${ }^{7}$

Various types of thrombi associated with CVC are pericatheter fibrin sheath, thrombotic occlusion of the catheter lumen and mural thrombus formation. Within a short period after insertion, there is deposition of platelet, fibrin and collagen on the surface of the catheter forming a sheath around it. ${ }^{8}$ This usually does not affect the catheter function but the fibrin sheath present at the tip can cause partial catheter occlusion resulting in failure to aspirate blood without interruption to flow of fluids. ${ }^{9}$ This fibrin sleeve promotes thrombus formation which can further progress to a mural thrombus characterised by thrombus beyond the catheter into the vein partially or completely occluding the vein. ${ }^{10}$ The international society of thrombosis and haemostasis recommends insertion of CVC on the right side and placing the tip of $\mathrm{CVC}$ at the venocaval junction to reduce the risk of thrombosis. ${ }^{9}$ 
Usage of less thrombogenic catheters, ultrasonographic guidance to reduce the number of attempts and improving the technique of insertion contributes in reducing the incidence. ${ }^{11,12}$ Hence we have selected the right sided IJV for cannulation and the tip of the catheter was placed at the venacaval junction under ultrasonographic guidance. However, CRT still poses a threat to life due to the low level of clinical suspicion.

In our study, majority of diabetics and hypertensives belonged to the age group of 5070 years and we did not find any statistically significant difference in sex distribution.

Occurrence of venous thromboembolism is twofold higher in diabetics than in nondiabetics. ${ }^{13}$ Diabetes can lead to various abnormalities in the coagulation and fibrinolytic system resulting in a procoagulant state which accounts for CRT. Hyperglycaemia induced increased blood viscosity, hyperfibrinogenaemia, endothelial injury, increased platelet reactivity, increase in Von Willebrand factor and other endothelium derived mediators are predisposing factors for the prothrombotic state. Alterations in the gene encoding platelet endothelial cell adhesion molecule (PECAM-1) and plasminogen activator inhibitor-1 (PAI-1) leads to ineffective fibrinolysis and glycation of fibrinogen forms a rigid and dense clot that is resistant to fibrinolysis in diabetics. ${ }^{4,14,15}$

Hypertension leads to a thrombogenic state due to rheological, haemostatic, endothelial and platelet abnormalities. Enhanced Tissue factor (TF) expression leading to disruption of the balance between the procoagulant and anticoagulant mechanism and disturbance in the vascular endothelial surface leads to propensity of thrombus formation in hypertensives. ${ }^{5}$ Studies have shown that higher levels of red cell distribution width in pre-hypertension and hypertension independent of age, inflammatory status and anaemia is one of the contributing factors. Lei Huang et.al. ${ }^{16}$ stated that DVT formation after orthopaedic surgery was more common among patients with hypertension. Anders G Holst et.al. ${ }^{17}$ observed that diastolic blood pressure $>100 \mathrm{mmHg}$ was an independent risk factor for VTE where as Ageno W et.al. ${ }^{18}$ found no relation between hypertension and thrombus formation. However, the relation between hypertension and hypercoagulable state is still debatable.

CRT are asymptomatic most of the times. Symptoms when present range from mild features like swelling, redness, fever, infection, pain around the ipsilateral shoulder or jaw, to features of superior venacaval obstruction with dilated veins over the chest and life threatening thromboembolic events comprising of right heart thrombus and pulmonary embolism. ${ }^{6,11}$ Many patients also present with post thrombotic syndrome characterised by oedema, hyperpigmentation and pain. This occurs due to failure of the clot to resolve completely either due to lack of treatment, inadequate treatment or recurrence. The reasons for the wide range of incidence of CRT is multifactorial. ${ }^{1,6}$

In our study, we found that the rate of thrombus formation was greater in diabetics and hypertensives compared to ASA1 patients. John A Heit et.al ${ }^{19}$ stated that diabetes mellitus is associated with 1.4 fold increase in thromboembolic events and this rate further increases in post-surgical, hospitalised diabetics. When diabetics and hypertensives were compared with the control group, we found statistically significant increase in the rate of thrombus formation in diabetics whereas clinically but not statistically significant thrombus formation in hypertensives.

V. Petrauskeine et $\mathrm{al}^{13}$ retrospectively studied 302 adult patients diagnosed with DVT or PE and found a twofold increased risk of thrombosis in diabetics than in non-diabetics. Whereas Rash Kujur et.al ${ }^{8}$ did not find any relation between diabetes mellitus and CRT formation possibly because the study they conducted was on one hundred consecutive patients and not targeting on diabetic population.

When suspected, CRT can be diagnosed using various diagnostic modalities like ultrasonography, venography, computed tomography (CT) and magnetic resonance imaging (MRI). Among these venography is considered to be the gold standard modality but not very commonly employed as it is an invasive procedure and involves patient exposure to intravenous contrast agent and radiation. Ultrasonography being non-invasive, more economical, readily available and reliable is more commonly used. ${ }^{7}$ Hence we adopted this technique. 
In our study, majority of the thrombi were detected on third day after CVC insertion in diabetics and hypertensives whereas in control group we found CRT occurring mainly on the sixth day, suggesting a prothrombotic environment seen in diabetics and hypertensives. Serial ultrasonography revealed a marginal increase in the size of the thrombi in $58.3 \%$ of diabetics and $42.8 \%$ hypertensives which was clinically but not statistically significant.

Management of patients with CRT depends on whether the patient continues to need the CVC or not. As per the guidelines from American college of chest physicians, in patients who have developed CRT and no longer need the CVC, it can be removed after 3-5 days of anticoagulation therapy. For patients who have developed CRT and continue to need the CVC, anticoagulation is initiated and CVC is left in place unless there is life threatening or limb threatening complication or there is contraindication to anticoagulant therapy. Anticoagulation in such cases may be continued for at least three months. ${ }^{9}$ In our study, patients with CRT were started on thrombolytics and anticoagulants and referred to the vascular surgeon for further management. Various prophylactic measures have been tried in the past intending to prevent CRT formation but have not been very successful.$^{20}$

In our study, we have observed CRT formation in all the study groups. The rate of thrombus formation is higher in diabetics followed by hypertensives. Majority of the thrombi were detected as early as on the third day after the insertion of CVC.

There are certain limitations in our study. The sample size was small and limited to our institution. A large population based studies at multicentre level are required to know the precise relation between CRT formation in diabetes and hypertension. We have used Doppler ultrasound, instead gold standard contrast venography may be a better diagnostic modality.

\section{Conclusion}

Both diabetics and hypertensives are more prone for catheter related thrombus formation. The rate of thrombus formation is statistically high in diabetics but not in hypertensives compared to ASA1 patients in whom right IJV was cannulated under ultrasound guidance. Performing serial Doppler ultrasonography in patients who are more prone for thrombosis will help in early detection of the thrombus and its progression. Timely diagnosis and initiation of treatment will avoid further complications.

\section{References}

1. Van Rooden CJ, Tesselaar ME, Osanto S, Rosendaal FR, Huisman MV. Deep vein thrombosis associated with central venous catheters-a review. Journal of Thrombosis and Hemostasis. 2005;3:2409-19.

https://doi.org/10.1111/j.1538-

7836.2005.01398.x

PMid:15975139

2. Minet C, Potton L, Bonadona A, Hamidfar-Roy R, Somohano CA, Lugosi M, Cartier JC, Ferretti G, Schwebel C, Timsit JF. Venous thromboembolism in the ICU: main characteristics, diagnosis and thromboprophylaxis. Critical Care. 2015;19:287. https://doi.org/10.1186/s13054-015-1003-9 PMid:26283414 PMCid:PMC4539929

3. Geldsetzer P, Manne-Goehler J, Theilmann M, Davies JI, Awasthi A, Vollmer S, Jaacks LM, Bärnighausen $T$, Atun R. Diabetes and hypertension in India: a nationally representative study of 1.3 million adults. JAMA internal medicine. 2018;178:363-72.

https://doi.org/10.1001/jamainternmed.2017.809 $\underline{4}$

PMid:29379964 PMCid:PMC5885928

4. Zhang Y, Shi Y, Ye R, Shao N, Pan F, Lin Y, Wang S. Diabetes mellitus-associated hyperglycaemia is a risk factor for recurring deep vein thrombosis and post-thrombotic syndrome-a cohort study. International Journal of Clinical \& Experimental Medicine 2016 ;9.

https://pdfs.semanticscholar.org/acd9/e35029084 5b3f941c39aa1dc0617b8a80a5c.pdf

5. Mao X, Ait-Aissa K, Lagrange J, Youcef G, Louis H. Hypertension, hypercoagulability and the metabolic syndrome: A cluster of risk factors for cardiovascular disease. Bio-medical materials and engineering. 2012;22:35-48.

https://doi.org/10.3233/BME-2012-0688 PMid:22766701

6. Burns KE, McLaren A. A critical review of thromboembolic complications associated with central venous catheters. Canadian Journal of Anaesthesia. 2008 ;55:532-41. https://doi.org/10.1007/BF03016674 PMid: 18676389

7. Wall C, Moore J, Thachil J. Catheter-related thrombosis: a practical approach. Journal of the Intensive Care Society. 2016 ;17:160-7. https://doi.org/10.1177/1751143715618683 PMid:28979481 PMCid:PMC5606399 
8. Kujur R, Rao SM, Badwaik G, Paraswani R. Thrombosis associated with right internal jugular central venous catheters: A prospective observational study. Indian journal of critical care medicine: peer-reviewed, official publication of Indian Society of Critical Care Medicine. 2012;16(1):17.

https://doi.org/10.4103/0972-5229.94419

PMid:22557827 PMCid:PMC3338233

9. Baskin JL, Pui CH, Reiss U, Wilimas J A, Metzger ML, Ribeiro RC, Howard SC. Management of occlusion and thrombosis associated with long-term indwelling central venous catheters. The Lancet. 2009 ;374:159-69. https://doi.org/10.1016/S0140-6736(09)60220-8

10. Xiang DZ, Verbeken EK, Van Lommel AT, Stas $\mathrm{M}$, De Wever I.Composition and formation of the sleeve enveloping a central venous catheter. $\mathrm{J}$ Vasc Surg 1998;28:260-71.

https://doi.org/10.1016/S0741-5214(98)70162-4

11. Kamphuisen PW, Lee AY. Catheter-related thrombosis: lifeline or a pain in the neck? ASH Education Program Book. 2012 ; 638-44. https://doi.org/10.1182/asheducation.V2012.1.63 $\underline{8.3798656}$

PMid:23233646

12. Geerts W. Central venous catheter-related thrombosis. ASH Education Program Book. 2014 Dec 5;2014:306-11.

https://doi.org/10.1182/asheducation-2014.1.306 PMid:25696870

13. Petrauskiene V, Falk M, Waernbaum I, Norberg M, Eriksson JW. The risk of venous thromboembolism is markedly elevated in patients with diabetes. Diabetologia. 2005 ;48:1017-21.

https://doi.org/10.1007/s00125-005-1715-5 PMid:15778859

14. Stein PD, Goldman J, Matta F, Yaekoub AY. Diabetes mellitus and risk of venous thromboembolism. The American journal of the medical sciences. 2009;337:259-64.

https://doi.org/10.1097/MAJ.0b013e31818bbb8b PMid:19365171

15. Wang S, Zhao Y. Diabetes mellitus and the incidence of deep vein thrombosis after total knee arthroplasty: a retrospective study. The Journal of arthroplasty. 2013;28:595-7. https://doi.org/10.1016/j.arth.2012.07.023 PMid:23153599

16. Huang L, Li J, Jiang Y. Association between hypertension and deep vein thrombosis after orthopaedic surgery: a meta-analysis. European journal of medical research. 2016;21:13. https://doi.org/10.1186/s40001-016-0207-z PMid:27004410 PMCid:PMC4802612

17. Holst AG, Jensen G, Prescott E. Risk factors for venous thromboembolism: results from the Copenhagen City Heart Study.
Circulation.2010;121:1896-903.

https://doi.org/10.1161/CIRCULATIONAHA.10

9.921460

PMid:20404252

18. Tsai AW, Cushman M, Rosamond WD, Heckbert SR, Polak JF, Folsom AR. Cardiovascular risk factors and venous thromboembolism incidence: the longitudinal investigation of thromboembolism aetiology. Archives of internal medicine. 2002;162:1182-9.

https://doi.org/10.1001/archinte.162.10.1182 PMid:12020191

19. Heit JA, Leibson CL, Ashrani AA, Petterson TM, Bailey KR, Melton III LJ. Is diabetes mellitus an independent risk factor for venous thromboembolism? A population-based casecontrol study. Arteriosclerosis, thrombosis, and vascular biology. 2009;29:1399-405. https://doi.org/10.1161/ATVBAHA.109.189290 PMid:19542020 PMCid:PMC2735343

20. You T, Jiang J, Chen J, Xu W, Xiang L, Jiao Y. Necessity of heparin for maintaining peripheral venous catheters: A systematic review and metaanalysis. Experimental and therapeutic medicine. 2017;14:1675-84. https://doi.org/10.3892/etm.2017.4706 PMid:28810636 PMCid:PMC552617 